\title{
EVALUATION OF RETENTION OF TOOTH-COLORED VERSUS CAST METAL DENTAL CLASPS FOR A MANDIBULAR DISTAL EXTENSION PROSTHESIS
}

\author{
Mostafa Helmy Mostafa*
}

\begin{abstract}
The aim of this study was to compare the retention of two different forms of clasps in mandibular distal extension prosthesis, which were; the Conventional casted metal clasps \& the Tooth-colored acrylic resin clasps "Acetal resin".

Materials \& Methods: For the rationale of this clinical investigation, fifteen patients were selected from the Outpatient Clinic of the Prosthodontic Department, Faculty of Oral and Dental medicine, Cairo University in accordance with certain criteria. Every patient got a skeleton parial denture that was constructed in a conventional manner. A hole was made in the middle of the lingual plate during fabrication of the framework; A Retention Measuring-Aided Device was made to allow attachment of the digital Forcemeter to this hole for measuring retention. Then, the metal clasp was removed and replaced by acetal resin clasp and the same procedures of measuring retention were performed in the same manner. Retention of the two clasp types was measured four times (at time of insertion, one month, two months and three months, respectively), by the aid of a prefabricated device (The Retention Measuring-Aided Device) for precise reproducible measurement.
\end{abstract}

Results: There was a statistically significant difference $(P \leq 0.05)$ in the mean Forcemeter measurements from base line to one month. Later, from one month to 2 months and from 2 months to 3 months; there was a statistically insignificant difference $(P \geq 0.05)$ in the mean Forcemeter measurements.

Conclusions and recommendations: Using Tooth-colored dental clasps would not compromise the retention of removable partial denture and can help to enhance the esthetics of removable partial dentures.

KEYWORDS: Acetal resin, Cobalt-chromium, Forcemeter, Retention, Esthetic clasps

\section{INTRODUCTION}

In general, the most important goal of any dental restoration is to replace the missing teeth.
Restoration is the broadest term for any artificial substance or prosthesis that replaces any lost structure of the missing teeth or oral tissues. ${ }^{(1,2)}$

* Lecturer of Removable Prosthodontics, Faculty of Dentistry, Cairo University 
Removable partial dentures come in two types; One is designed for short-term performance and is called a temporary (interim or provisional) partial denture, while the other type is designed for longerterm performance, and is called a definitive (permanent) prosthesis. Both are specified in different situations, using different philosophies, techniques, materials and methods of manufacture. ${ }^{(3)}$

Many patients are looking for removable partial dentures (RPD) for medical, anatomical, psychological or financial reasons. These patients deserve more benefits from partial denture prosthetic therapy in terms of improved aesthetic outcome. The ugly display that is associated with conventional metal clasps can be considered a challenge for any prosthodontist. ${ }^{(4-6)}$

Different studies reported that the traditional use of metal clasps, such as cobalt-chromium (Co-Cr) disturbs the esthetics and subsequently affects patient's prosthetic confidentiality. Recently, esthetically accepted clasps have been introduced as a solution for the non-esthetic appearance of the most commonly used alloys for clasp fabrication. ${ }^{(7-10)}$

Acetal resin material is one of those recently introduced esthetically-accepted material, which is available in twenty different shades (14 of which vita shades, 3 pink shades and 3 extra shades). ${ }^{(11,12)}$

With the aim of appearance improvement of metal clasps and to obtain superior esthetics, a toothcolored material made from thermoplastic resin have been used. However, there is little information in the literature on the long-term success of such clasps regarding retention. ${ }^{(13-15)}$

In order to clarify the retentive properties of those tooth-colored dental clasps, a comparison will be made with the traditionally-used cast metal clasps in distal extension prostheses.

The null hypothesis was that; there will be no significant difference between the two clasp designs in terms of retention throughout the entire study period.

\section{MATERIALS \& METHODS}

Fifteen patients were selected from the Outpatient Clinic of the Prosthodontic Department, Faculty of Oral and Dental medicine Cairo University according to the following criteria:

- Middle-aged patients between 30-45 years.

- Both sexes were selected.

- Co-operative patient obeying clinician's instructions.

- Patients revealed mandibular class one Kennedy classification.

- Patient's had normal maxillo-mandibular relationship.

- Patients were free from any systemic or debilitating diseases, which may affect denture retention and/or salivary secretions.

- Patients presented with normal temporomandibular joint function.

After taking full patient's personal, medical and dental history, each patient received a thorough clinical and radiographic examination.

The patients were asked for their approval to the conduction of the research \& being recalled for follow-up appointments. All details were written \& signed by the patients in consent forms.

The study was conducted according to principles stated in Helsinki Declaration \& being approved by the Institute ethical committee.

\section{Construction of the Removable Partial Denture (RPD):}

- Upper and lower primary impressions were made utilizing irreversible hydrocolloid impression material* according to the manufacturer's instructions and poured into stone plaster ${ }^{*}$ to obtain diagnostic casts on which

\footnotetext{
* Cavex alginate, dust free, high consistency, Holland.
} 
acrylic resin $^{* *}$ special trays were fabricated. (Fig. 1\& 3)

- Upper and lower study casts were obtained. For every patient, the upper cast was mounted on a semi-adjustable articulator ${ }^{* * *}$ according to a face bow ${ }^{* * * *}$ record and the lower cast was mounted on the articulator by the aid of centric jaw relation record. (Fig.2)

- Mouth Preparations were carried out by preparing a mesial rest seat on each abutment adjacent to the edentulous area. Where, the rest seats were made triangular in shape with rounded apex and angles and extending to involve the middle $1 \backslash 3$ of the buccolingual cusp tips, and mesio-distally to involve 113 of the mesio-distal dimension. (Fig.4)

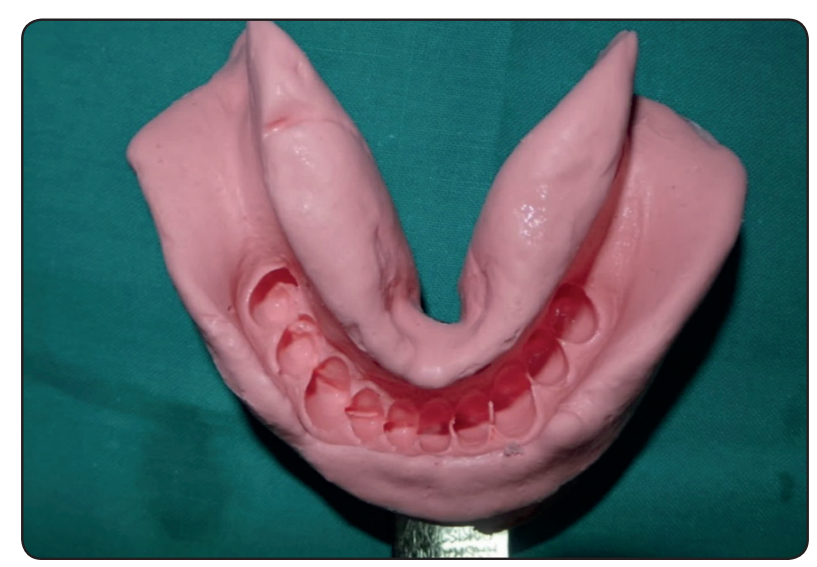

Fig (1): primary impression.

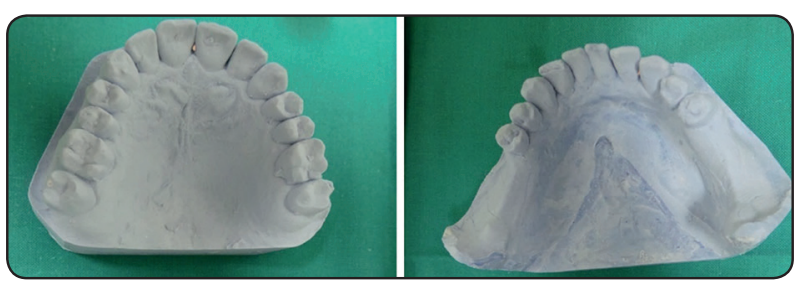

Fig (2): Upper \&lower study casts.
- Final impressions were made using irreversible hydrocolloid impression material ${ }^{*}$ according to the manufacturer's instructions and poured into investment material ${ }^{* * * * * *}$ to obtain the refractory casts.

- A master cast was obtained, then a wax pattern was constructed on the cast with a mesial occlusal rest on the abutment tooth near the edentulous area connected to a lingual plate and with a minor connector with a bracing arm originating from it to provide bracing for the RPD whilst its retention is gained from a gingivally- approaching clasp.

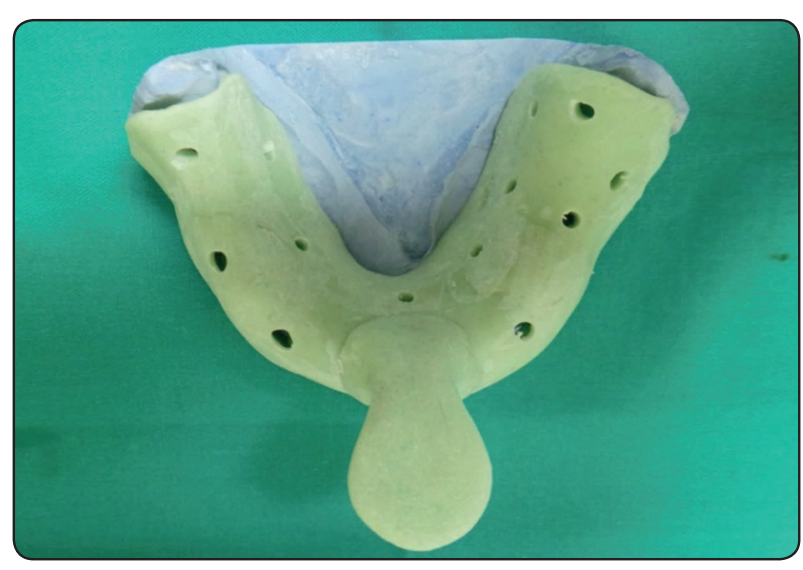

Fig (3): Acrylic resin special tray.

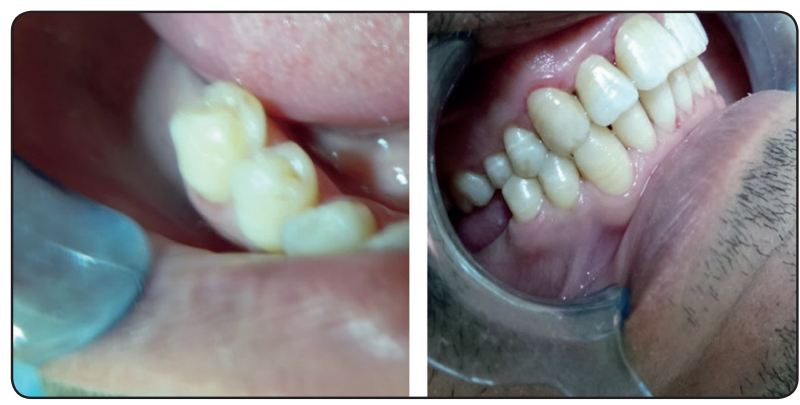

Fig (4): Rest seat preparation.

\footnotetext{
* Type III dental stone Lascod SP, sestofino, Italy. ** Moldano. Bayer Leverkusen, pekatray, Germany. *** Bio. Art articulator 5000, Brazil. **** Bio. Art facebow 5000, Brazil. ***** Obtivest, DeguDent, Hanau, Germany.
} 
- At the try in stage of the metal frame work, an index was made for the wax pattern of the gingival approaching clasp to acquire standardize clasps of different material but of the same size, diameter and length. Then construction of the metallic RPD was carried out in a conventional manner.

- A hole was made in the middle of the lingual plate during fabrication of the framework; The Retention Measuring-Aided Device was constructed to allow attachment of the Digital

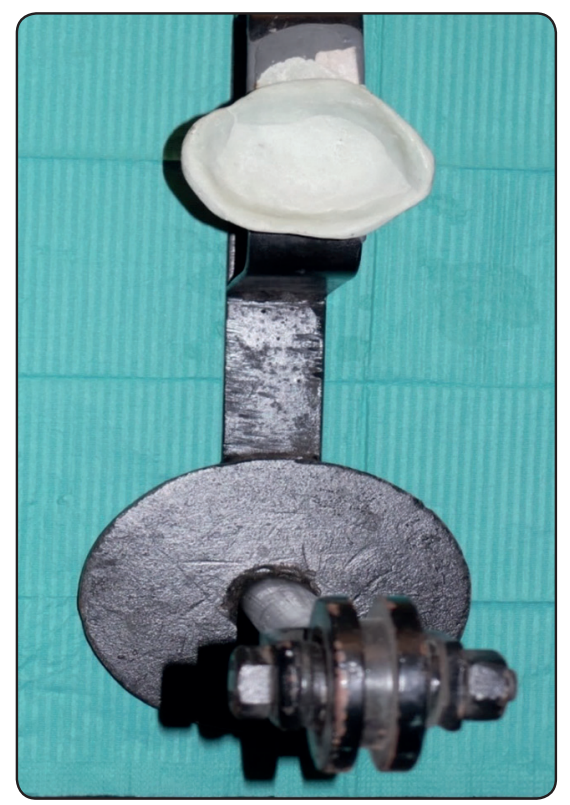

Fig (5): The prefabricated device (The Retention MeasuringAided Device)

\section{Forcemeter * to this hole. (Fig.5)}

- Retention of the CO-CR clasp was measured by utilizing a Digital Forcemeter. Where, retention of Co-Cr clasp was measured Four times (at time of insertion, one month, two months and three months, respectively), by the aid of the
Retention Measuring-Aided Device for accurate reproducible measurement.

\section{Construction of The Retention Measuring-Aided Device:}

- This device composed of chin support that is connected to a vertical arm with rotatory wheel, the patient set on a special acrylic chin support that allow the patient to be sitting in the same reproducible position during the successive measurement visits.

- Downward tension was applied using the digital force meter which was attached to the denture by a nylon wire through the rotation wheel to the prosthesis in the patient mouth.

- The (Co-Cr) clasp was removed and substituted by acetal resin clasp** by returning of the metal framework to the stone cast, then the clasp was waxed by the index. Wax was adapted into its position on the buccal surface of the abutment teeth. The clasp was waxed to cast framework to ensure a solid connection between them.

- The model was placed in the injection flask using laboratory stone. Clasp arms were then sprued then the flasking was completed and allowed to set. When the flask was set, it was reopened and the wax was removed with boiling water, the acetal resin was injected in the mold and the flask was closed for curing according to the manufacture instruction.

- After curing and cooling of the flask, it was opened and the metal framework with acetal resin clasp was removed from the flask and the acetal clasp was finished and polished. The RPD was finished in a conventional manner and received by the patient. (Fig.6)

- Retention of RPD Framework with the acetal resin clasp was measured by using a Digital Forcemeter; (Fig.7) four times (at time of insertion, one month, two months and

\footnotetext{
* Electronic scale, OCS - 5 A, EXETEC, Germany.

** T.S.M Acetal Dental Resin for Tooth-Colored Clasps, Talladium, UK.
} 


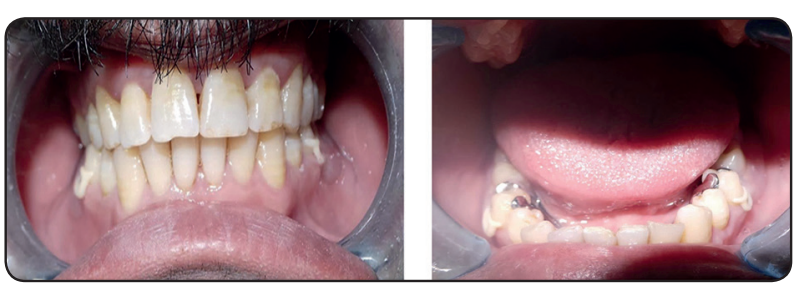

Fig (6): The acetal resin clasp in the finished RPD intra-orally.

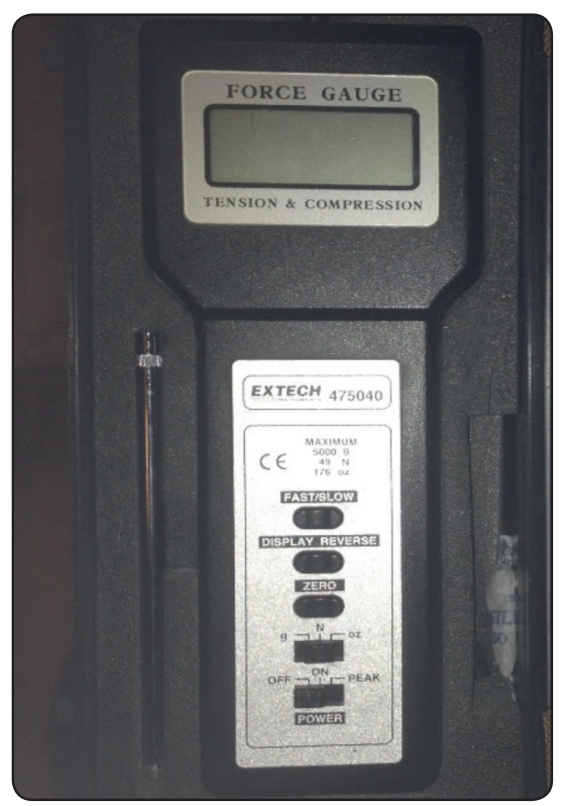

Fig (7): Digital Forcemeter.

three months, respectively), by the aid of a prefabricated device (The Retention MeasuringAided Device) for accurate reproducible measurement.

- The patient sat in the dental chair, so that the occlusal plane of the maxillary teeth was parallel to the floor. Patients were asked to fix their heads during the steps of examination.

- All the results were calculated, tabulated and then statistically analyzed.

\section{Statistical analysis}

Data were presented as means and standard deviation (SD) values.

\section{Statistical tests}

The data was expressed as means \pm standard deviations and mean percentage changes.

For parametric data; Repeated measures Analysis of Variance (ANOVA) was utilized to study the changes by time. Bonferroni's post-hoc test was performed for pair-wise comparisons when ANOVA test is significant.

\section{Significance level}

The significance level was set at $\mathrm{P} \leq 0.05$. Statistical analysis was performed with SPSS 20* (Statistical Package for Scientific Studies) for Windows.

\section{RESULTS}

Numerical data were explored for normality by checking the distribution of data and using tests of normality (Kolmogorov-Smirnov and ShapiroWilk tests). Forcemeter measurement data showed normal (parametric) distribution.

Data were presented as mean and standard deviation (SD) values. For parametric data; Repeated measures Analysis of Variance (ANOVA) was utilized to study the changes by time. Bonferroni's post-hoc test was performed for pairwise comparisons when ANOVA test is significant.

The significance level was set at $\mathrm{P} \leq 0.05$. Statistical analysis was performed with IBM ${ }^{\circledR}$ SPSS ${ }^{\circledR}$ Statistics Version 20 for Windows. 


\section{Forcemeter Measurements:}

The mean and standard deviation values of Forcemeter measurements were calculated at time of insertion, one month, two months and three months respectively.

There was a statistically significant difference $(P \leq 0.05)$ in the mean Forcemeter measurements from base line to one month between the two clasp designs (in favour of Co-Cr clasps).

From one month to two months \& from two months to three months; a statistically insignificant difference $(P \geq 0.05)$ was observed in the mean Forcemeter measurements between the two clasp designs.

TABLE (I): The mean, standard deviation (SD) values and results of repeated measures ANOVA test for comparison between retention values in the two designs as well as changes by time for each clasp:

\begin{tabular}{|c|c|c|c|c|c|}
\hline \multirow{2}{*}{ Time } & Measp Design & Cr-Co & \multicolumn{2}{|c|}{ Acetal R. } & P-value \\
\cline { 2 - 5 } & Mean & SD & $\begin{array}{c}\text { Cetween } \\
\text { both) }\end{array}$ \\
\hline At insertion & 69.4 & 1.5 & 66.3 & 4.1 & 0.175 \\
\hline 1 month & 66.34 & 3.5 & 59.34 & 5.5 & $0.045^{*}$ \\
\hline 2 months & 64.33 & 5.7 & 58.33 & 4.7 & 0.097 \\
\hline 3 months & 55.53 & 4.2 & 55.49 & 3.3 & 0.841 \\
\hline
\end{tabular}

* Significant at $P \leq 0.05$, Different superscripts in the same column are statistically significantly different

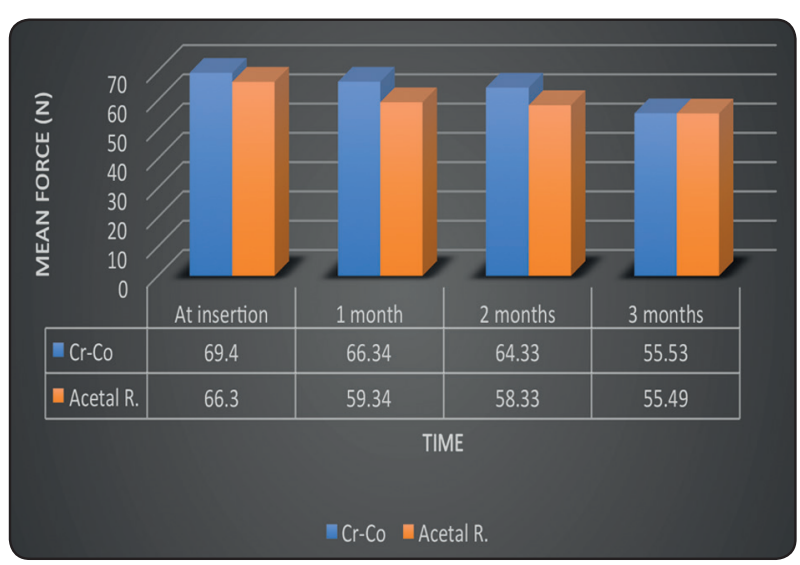

Fig. (8): A chart representing mean retention values in the two designs.

\section{DISCUSSION}

\section{Discussion of Methodology}

In this investigation, the restoration of esthetics was a vital factor to be considered in fabrication of a removable partial denture. Different forms of polymers and metal alloys have been used in RPD construction. The most generally utilized metals are stainless steel (wrought wire), Co-Cr alloys and gold-titanium alloys, despite the fact that these can be unaesthetic. ${ }^{(15)}$

The greater awareness of aesthetics in dentistry has brought about the need for removable partial dentures that exhibit little or no metal structures (either supporting or retentive components). ${ }^{(16)}$

In vitro applications suffer from several inadequacies. First, the denture mobility in vivo is subjected to mechanical considerations, in addition, it depends on the neuromuscular activity of the patient. Second, the pattern of loading in the mouth is far more complicated than the application of load in vitro. Finally, the oral mucosa is simulated with soft acrylic material which is totally different than the natural mucosa in the patient mouth. ${ }^{(17,18)}$ Based on the previous explanation, this study was carried out clinically on patients.

Retentive clasp arm must be capable of flexing and returning to their original form and should retain a RPD satisfactorily. The clinical experience of the loss of RPD retention after the prosthesis is worn for some time provoked a question of; whether constant bending of the clasp during insertion and removal of the denture fatigues the clasp? ${ }^{(19-21)}$

\section{Regarding Patient selection}

Patients ranging from 30-45 years were selected, as changes that might happen for the patient within this age range are not extreme and therefore the consistency and standardization of the results was assured. Furthermore, patients at this age are co-operative and have proper neuromuscular control. Age may ruin central processing of the 
nerve impulses, obstruct the activity of muscles \& consequently elder people usually presented with weak neuromuscular control. ${ }^{(22)}$

Patients were selected from both sexes as the difference in sex will have no effect on the retention.

Patients were selected free from systemic diseases which could affect denture retention (e.g. Parkinson's disease, hemiplegia or any abnormalities in the temporomandibular joint), as these might result in prosthetic failure due to improper neuromuscular control. ${ }^{(23)}$

Patients having healthy firm muco-periosteum with well-developed ridges \& without any signs of inflammation or flabbiness covering the edentulous ridge, to prevent denture base movement over the redundant tissues which could affect denture base stability and consequently provide inaccurate readings during testing the retention quality of the denture. ${ }^{(24-26)}$

Primary impression was made for every patient utilizing irreversible hydrocolloid and poured instantly into stone cast to avoid dimensional changes of the hydrocolloid. ${ }^{(27)}$

The trial denture bases were made and a maxillary face bow record was utilized to mount the upper cast, in order to orient the maxillary cast in its accurate position in relation to the temporomandibular joint. ${ }^{(28)}$

Each patient was seated in the dental chair, so that the occlusal plane of upper teeth kept parallel to the ground floor. Patients were asked not to change their head position during the steps of investigation, in light of the fact that any changes in head posture might influence the direction and length of traction and hence, less precise readings. ${ }^{(29-32)}$

Ten readings were spotted for each type of clasp at delivery to limit any errors from the operator, five minutes were permitted between each measurement to ensure complete return of the force meter to the zero reading and to allow complete seating of the denture and standardization of the experiment conditions. Another ten readings were spotted after one month, two months \& three months from delivery to assess any changes of the retention. ${ }^{(33,34)}$

\section{Discussion of Results}

In this study, all the factors that control retention were maintained throughout the study period by having the same patient using the same partial denture and only the type of clasps were changed. ${ }^{(35-39)}$

The purpose of the use of this tooth-colored type of resin (Acetal resin) for clasp fabrication is to enhance the esthetic appearance of the clasps and to avoid using metal clasps on anterior teeth. ${ }^{(40-42)}$

Many authers (43) endorsed that in clinical usage of Acetal resin, the retentive clasp should attain a shorter length, moderately greater crosssectional area, and engage deeper undercuts to have satisfactory retention. Likewise, others ${ }^{(44)}$, stated that "to gain acceptable retention from acetal resin clasp, the clasp should attain a larger crosssectional area than a metal clasp. On the contrary in this study, a uniform thickness of the wax pattern was employed for fabrication of the acetal clasp and Co-Cr clasp.

Regarding the results obtained; there was a non-statistically significant difference in the mean Forcemeter measurements, from one month to two months \& from two months to three months which might be attributed to increased physiologic retentive forces as a result of increased denture adaptation with the surrounding musculature. ${ }^{(45-47)}$

The results of the present clinical investigation confirmed the null hypothesis previously established.

\section{CONCLUSION}

This investigation was performed to analyze the impact of two different partial denture clasps on the retention of definitive distal extension mandibular Removable Partial Denture.

\section{From the results of this study, the following con- clusions could be achieved:}

- Using esthetic clasp material would not compromise the retention of removable partial denture and can help to improve esthetics in RPDs. 
- The Forcemeter measurements were accurate \& favorable for measuring retention of the removable partial denture clasps.

- More clinical investigations with larger sample sizes and over larger time scale, are still needed.

\section{Conflict of Interest}

This clinical study was self-funded by the author, with no conflict of interest.

\section{ACKNOWLEDGMENT}

I would like to express my most sincere gratitude and grateful appreciation to my dearest friend $\boldsymbol{d r}$. Abd Elmonem Wahby El Ansary for his valuable effort and great cooperation.

\section{REFERENCES}

1. The Glossary of Prosthodontic Terms: The Academy of Prosthodontics. $8^{\text {th }}$ ed. J. Prosth. Dent.; 94: 10-88, 2005.

2. Arda T. and Arikan A.: An in vitro comparison of retentive force and deformation of acetal resin and cobalt-chromium clasps. J Prosthet Dent 94:267-74, 2005.

3. Rosenstiel SF, Fujimoto J and Land ME: Contemporary fixed prosthodontics. Mosby Inc. St. Louis.; $3^{\text {rd }}$ ed.: 673696, 2001.

4. Mc Cracken's: Removable partial prosthodontics Quintessence publishing CO.; $11^{\text {th }}$ ed.: pp.: 24-113, 2000.

5. Rodney D. Pboenix, David R. Cagna and Ceberles F. DeFreest: Stewart's clinical removable partial prosthodontics. Quintessence publishing CO.; $2^{\text {nd }}$ ed.: pp.: 15-320, 2000.

6. Eliason CM: Clasp design for distal-extension removable partial dentures. J prosthet Dent 49:25-27,1983.

7. Bernd Wastmann, Eiko Mushimoto and Afrodite Sofou : Indications for Removable Partial Dentures: Aliterature Review . int J Prosthodont 18: 139-145, 2005.

8. Kapur KK, Garrett NR, Dent RJ, Hasse AL: A randomized clinical trial of two basic removable partial denture designs. Part II: Comparisons of masticatory scores. J Prosthet Dent 78:15-21, 1997.

9. Zarb GA, Bolenders CL and Carlsson GE: Boucher's prosthodontic treatment for edentulous patient. $11^{\text {th }}$ edition. Mosby, St. Louis, Missouri; pp.: 525-528, 1997.
10. Kapur KK.: Veterans Administration Cooperative Dental Implant Study-Comparisons between fixed partial dentures supported by blade-vent implants and removable partial dentures. Part III: Comparisons of masticatory scores between two treatment modalities. J Prosthet Dent. 65:272283,2005

11. Locker D, Clarke M, Payne B: Self-perceived oral health status, psychological will-being, and life satisfaction in an older adult population. J Dent res 79:970-975, 2000.

12. Appollonio I, Carabellese C, Frattola A, Trabucchi M.: Influence of dental status on dietary intake and survival in community-dwelling elderly subjects. Age Ageing 26:445456, 1997.

13. Mojon P, Budtz-JOrgensen E, Rapin CH.: Relationship between oral health and nutrition in very old people. Age Ageing 28:463-468, 1999.

14. Veeraiyan DN, Ramalingam K and Bhat V: Textbook of prosthodontics, $4^{\text {th }}$ ed. Jaypee Bros., New Delhi; pp. 464 477, 2007.

15. Thomas, D., John, R. and Theodora, V.: Implant prosthodontics, current perspective and future direction. Quintessence; 15: 1, 2005.

16. Jepson N, Alien F, Moynihan P, Kelly P, Thomason M.: Patient satisfaction following restoration of shortened mandibular dental arches in a randomized controlled trial. Int J Prosthodont 6:409-414, 2003.

17. Tallents RH, Macher Dj, Kyrkanides S, Katzberg RW, Moss ME.: Prevalence of missing posterior teeth and intraarticular temporo-mandibular disorders. J Prosthet Dent 87: 45-50, 2002.

18. Türp JC, Strub JR.: Prosthetic rehabilitation in patients with tem-poromandibular disorders. J Prosthet Dent 76:418-423, 1996.

19. Parvizi A, Lindquist T, Schneider R, Williamson D, Boyer D, Dawson DV: Comparison of the dimensional accuracy of injection molded base materials to that of conventional pressure pack acrylic resin. J. Prosthodont 13(2): $13-9,2004$

20. Brudvik J and Reimers D: The tooth-removable partial denture interface. J. Prosth. Dent.; 68: 924-927, 1992.

21. Budtz-Jorgensen E: Alternative framework designs for removable partial dentures. J. Prosth. Dent.; 80 (1): 58-66, 1998.

22. Vermeulen AH, Keltjens HM, van't Hof MA Käyser AF.: Ten-year evaluation of removable partial dentures. Survival rates based on retreatment, not wearing and replacement J Prosthet Dent 76: 267-272, 1996. 
23. Henry MY, Charles TS and Dean M: Comparative in-vitro evaluation of two provisional restorative materials. J. Prosth. Dent.; 85: 129-132, 2001.

24. Budtz-JOrgensen E, Bochet G, Grundman M, Borgis S.: Aesthetic considerations forthe treatment of partially edentulous patients with removable dentures. Pract Periodontics Aesthet Dent 12:765-772, 2000.

25. Donovan T.E., Derbabian K., Kaneko L., and Wright R. Esthetic considerations in removable prosthodontics. J Esthet Restor Dent 13:241-53, 2001.

26. Brudvik J.S. and Palacios R.: Lingual retention and the elimination of the visible clasp arm. J Esthet Restor Dent 19:247-54; discussion 255, 2007.

27. Zarb G.A, Bolender C.L., Hickey G.C and Carlesson C.E: Boucher's prosthodontic treatment for edentulous patients. $10^{\text {th }}$ ed. St Louis,.V. Mosby 10. (1990); p 177.

28. Phoenix, R.D., Cagna, D.R. and De Freest, C.F.: Clinical removable prosthodontics. Quintessence publishing Co., Inc., $3^{\text {rd }}$ ed. Moscow, Prague, Warsaw p63-89, 2003.

29. Davenport J.C., Basker R.M., Heaith J. R., Ralph, J.P., Glantz P.O. and Hammond P.: Clasp design: Britt. Dent. J. 190(2):27, 2001.

30. Vander Brink J.P., Wolfaardt J.F. and fulkner M.G.: A comparison of various removable partial denture clasp materials and fabrication procedures for placing clasps on canine and premolar teeth. J. Prosthet Dent 70:180-864, 1993.

31. Vallittu P.K and Miettinen T.: Duration of induction melting of cobalt chromium alloy and its effect on resistance to deflection fatigue of cast denture clasps. J. Prosthet Dent 75: 332-336, 1996.

32. Lavere A.M.: Clasp retention; the effect of the variables. J. Prothodont. 2:126-31, 1993.

33. Vallitu P.K. and kokkonen M.: Deflection fatigue of cobalt chromium, titanium and gold alloy cast denture clasp. J. Prosthet Dent. 74:412-421, 1995.

34. Kim D.S, Park C.T, Jin Y.: comparison of cast Ti-Ni alloy clasp with conventional removable partial denture clasps. J. Prosthet Dent 91:374-382, 2004.

35. Bridgeman J.T., Marker V. A., hummel S.K., Benson B.w., Pace L.L.: Comparison of titanium and cobalt chromium removable partial denture clasps. J. Prosthet Dent 78: 187193, 1997.
36. Phoenix R.D., Mansueto M.A and Ackerman N.A. et al.: Evaluation of mechanical and thermal properties of commonly used denture base resins, J prosth. 13(1): 17-27, 2004

37. Budtz, Bochet G., Grudman M. and Borglis S.: Aesthetic consideration for the treatment of partially edentulous patients with removable dentures 12:765-772, 2002.

38. Donovan T.E. and Cho G.C.: Esthetic consideration with removable partial denture, J. Calif Dent. Assoc. 31(7): p.551-557, 2003.

39. Jean C. Wu, George H., Latta Jr, Russell A.: In vitro deformation of acetyl resin and metal alloy removable partial denture direct retainers. J. Prosthet. Dent. 90:586-90, 2003.

40. Mahmoud A. A., Wakabayashi N., and Takahashi H.: Prediction of permanent deformation in cast clasps for denture prostheses using a validated nonlinear finite element model. Dent Mater 23:317-24, 2007.

41. Rodrigues R.C., Ribeiro R.F., de Mattos Mda G., and Bezzon O.L.: Comparative study of circumferential clasp retention force for titanium and cobalt-chromium removable partial dentures. J Prosthet Dent 88:290-6, 2002.

42. Sato Y., Tsuga K., Abe Y., Asahara S., and Akagawa Y.: Finite element analysis on preferable I-bar clasp shape. J Oral Rehabil 28:413-7, 2001.

43. Turner J.W., Radford D.R., and Sherriff M.: Flexural properties and surface finishing of acetal resin denture clasps. J Prosthodont 8:188-95, 1999.

44. Fitton J.S., Davies E.H., Howlett J.A., and Pearson G.J.: The physical properties of a polyacetal denture resin. Clin Mater 17:125-9, 1994.

45. Oretgon SM, Thompson G.A, Agar JR, Tyalor TD, Perdikis D: Retention force of spherical attachment as a function of implant and matrix angulation in mandibular over denture: an in vitro study. J. Prosthet Dent 101(4)231$8,2009$.

46. Aziz K.A.: The effect of three attachment types on retention characteristics and load distribution in implant supported mandibular over dentures. (In vitro study). M.D.S. thesis faculty of Dentistry, Cairo University, 2008.

47. Ozkan Y., Arikan A., Akalin B., and Arda T.: A study to assess the colour stability of acetal resins subjected to thermocycling. Eur J Prosthodont Restor Dent 13:10-4, 2005. 